\title{
Bipolar radiofrequency-induced thermotherapy of haemorrhoids: a new minimally invasive method for haemorrhoidal disease treatment. Early results of a pilot study
}

\author{
Jiri Duben, Lukas Hnatek, Bohumil Dudesek, Petr Humpolicek, Jiri Gatek \\ Surgical Department, Hospital Atlas Zlin, Tomas Bata University, Zlin, Czech Republic
}

Videosurgery Miniinv 2013; 8 (1): 43-48 DOI: $10.5114 /$ wiitm.2011.30824

\begin{abstract}
Introduction: Haemorrhoidal disease is the most frequent benign anorectal disease. Conservative, minimally invasive and surgical methods are used in the treatment of haemorrhoidal disease. Radiofrequency thermoablation is a popular new technique in the treatment of varicose veins.

Aim: Assessment of the use of the method in the treatment of haemorrhoidal disease using bipolar radiofrequencyinduced thermotherapy (RFITT or so-called Celon method).

Material and methods: We used the CelonLab PRECISION (Celon AG medical instruments, Teltow, Germany) with the bipolar RFITT applicator Celon PrOBREATH for the treatment of haemorrhoidal disease stages III and IV.

Results: In the Department of Surgery at the Atlas Hospital in Zlin, Czech Republic, a total of 71 patients were treated from 9/2007 to 10/2010 with this new treatment approach. The success rate was 100\%, local recurrence rate was $2.8 \%$, and medium-term satisfaction of patients who underwent the procedure was $99.5 \%$. Complications appeared in $4.26 \%$ of cases.

Conclusions: The new RFITTH technique for treatment of advanced stages of haemorrhoidal disease is a new treatment modality with good curative response, low level of complications, minimum pain and quick return of patients to their usual activities.
\end{abstract}

Key words: haemorrhoids, radiofrequency, minïnvasive technique.

\section{Introduction}

Haemorrhoidal disease is the most frequent benign anorectal disease. The extent of haemorrhoidal disease is determined according to the Goligher classification (stages I-IV). The aim of successful treatment is to reduce blood flow in the haemorrhoidal plexus, decrease prolapse and preserve a maximum of anoderm mucosa [1]. Conservative, minimally invasive and surgical methods are used in the treatment of haemorrhoidal disease.
Parks', Ferguson's [2], Whitehead's, and MorganMilligan's procedures are the classic surgical treatments of more advanced stages of haemorrhoidal disease. All these methods are efficient in the long term, but they bring significant post-surgery pain and complications. The excision reduces anoderm tissue with the risk of worsening sensory perception of stool messaging. It also brings the danger of long-term complication presenting as post-surgery stenosis of the anus. New surgical techniques described by Longo and Doppler guided haemorrhoidal artery liga- 
tion (DG-HAL) decrease post-surgery pain but also reduce anal mucosa. Procedure for prolapsing haemorrhoids (PPH)-Longo achieves it through excision and HAL-RAR through folding [3-5].

\section{Aim}

The aim of our study was to develop a new treatment procedure suitable for more developed stages of haemorrhoidal disease (stages III + IV according to the Goligher scale). The new procedure has to limit blood flow in haemorrhoids, retract prolapsed haemorrhoids and preserve anoderm mucosa. The aim of the study is to assess the use of the method in the treatment of haemorrhoidal disease using bipolar radiofrequency-induced thermotherapy (RFITT or socalled Celon method).

\section{Material and methods}

Radiofrequency-induced thermotherapy (RFITT) allows one to have a locally concentrated impact of thermal energy on pathological tissue. With this purpose RFITT was used in the therapy of advanced haemorrhoids from 2007 to 2010 at Atlas Hospital in a prospective study that was approved by the ethical committee in June 2007. After successful patient recruitment the Celon method was used from September 2007 onwards [6].

We used the CelonLab PRECISION as an energy source that allows adjustable output as well as audiofeedback control of the radiofrequency energy on the haemorrhoids. As the RFITT generator shuts down automatically if the targeted impedance has been reached, under/overtreatment can be avoided. We chose to use the RFITT applicator (Celon ProBREATH), which is a bipolar electrode with a diameter of $1.1 \mathrm{~mm}$ and an application length of $10 \mathrm{~mm}$. Radiofrequency current flows just between the two parts of the bipolar electrode, forming a clearly defined coagulation area. The thermal effect in the tissue has a therapeutic impact on the endothelial lining of the vascular wall, leading to a well-controlled obliteration.

As the Celon system enables impedance feedback, electric current stops passing the tissue automatically upon termination of the coagulation. The RFITT can be applied safely thanks to an acoustic signal indicating the optimum coagulation stage. In the case of RFITT application for the treatment of haemorrhoids, high frequency electric current flows through haemorrhoidal tissue, which is in contact with the bipolar electrode, and heats it up to $80^{\circ} \mathrm{C}$. This leads to contraction of the vascular wall of the haemorrhoid, interruption of blood flow through the haemorrhoidal plexus, and retraction back into the anus.

Patients with haemorrhoidal disease in stages III (manually reducible prolapse) and IV (permanent prolapse) were included in the study. All patients were over 18 years old and fully capable of signing the informed consent. Proctoscopy or colonoscopy was performed in all patients before surgery. Laxative (YAL, RCT sol., Trommsdorff GmbH \& Co. KG, Arzneimittel, Alsdorf) was applied an hour before the procedure. The preoperative protocol included information on age, height, weight, associated diseases, previous surgery or interventions on haemorrhoids, disease stage, subjective complaints - bleeding frequency (daily, weekly, monthly), pain (using a visual analogue scale, 0-10), prolapse, itching, mucus, necessity of analgesics. The surgery was performed under general, epidural or spinal anaesthesia. A transparent proctoscope (BEAK, Sapimed) was put in the anus and haemorrhoidal plexuses were detected visually. After having set the CelonLab PRECISION at the power level of $5 \mathrm{~W}$ the bipolar RFITT electrode was inserted after tumescence with saline solution into the haemorrhoidal nodes and extracted gradually. The progress of the coagulation was monitored via acoustic feedback as well as visually while extracting the RFITT applicator. Then followed, if necessary, application of the bipolar electrode into prolapsing haemorrhoids distally from the linea dentata. Patients were discharged on the same or next day. Outpatient care consisted of laxatives (Lactulosa Biomedica) + venotonics (Detralex, Les Laboratoires Servier, Neuilly-SurSeine, $3 \times 2 \mathrm{tbl}$.) During the surgery day the patients were permanently monitored, local status was checked for bleeding and analgesics were applied according to the individual needs. Patients with urine retention were catheterised. The number of insertions of the RFITT applicator, the device output, the time for the intervention, and the application time associated with the RFITTH procedure (excisions, sphincter divulsion) were recorded after surgery. Post-surgery followup consisted of patients' assessment of the symptoms such as bleeding (important, spotting through day, spotting only after stool), pain, patients' satisfaction as well as objective assessment of clinically rele- 
vant symptoms such as oedema, haematoma, finding in per rectum examination. All patients were followed up in 7 and 21 day intervals after surgery. Local status was controlled and a rectum examination was performed during each visit. Oedema, pain and bleeding were recorded during each follow-up visit. All patients were examined again 6 months and 1 year after RFITTH using the same examination criteria. At the same time patients' opinion regarding their satisfaction with RFITTH and their further recommendations were assessed. In January 2010 a final questionnaire was sent to all patients. $35 \%$ of all patients returned the questionnaire. Results are shown in Table I.

\section{Statistical analysis}

The statistical assessment was performed in the Institute for Statistics and Bioanalysis of Tomas Bata University in Zlin, Czech Republic using SAS CATMODE procedure for Windows.

\section{Results}

Between September 2007 and October 2010, RFITTH was performed on 71 patients in advanced stages of haemorrhoidal disease. Among this patient population, 35 and 36 patients were in stage III and IV, respectively. The main number of RFITT applications in the area of internal haemorrhoids proximally from the linea dentata (Internal in Chart 1) for 71 patients was 14.59 with a median of 14.0 (10-31 punctures). Applications on prolapsing haemorrhoids were performed in 36 patients. The main number of RFITT applications on prolapsing haemorrhoids distally from the linea dentata was 3.42, median 3.5 (1-8 punctures). External puncture (distally from the dentate line) had to be applied more frequently by patients in stage IV than in patients in stage III. The difference is evident at significance level 0.0004 .

We monitored the patient's pain according using a visual analogue scale on the $7^{\text {th }}$ and $21^{\text {st }}$ day after RFITTH. Oedema was present in 13 patients and minor bleeding (limited to smaller spots) was seen in 48 patients (Table II). The effect of the application side (internal/external puncture) on pain after 7 and 21 days was not statistically significant. No provable variances in appearance of blood and oedema in 7 and 21 days have been found because of the limited cohort.

Six patients experienced minor complications, with anal fissures ( 5 cases) being the most serious
Table I. Follow-up results

\begin{tabular}{|c|c|c|c|c|}
\hline $\begin{array}{l}\text { Year of } \\
\text { surgery }\end{array}$ & Prolapse & $\begin{array}{c}\text { Soreness } \\
\text { on defecation }\end{array}$ & Bleeding & $\begin{array}{l}\text { Recommen- } \\
\text { dation }\end{array}$ \\
\hline 2007 & 0 & 0 & 0 & Yes \\
\hline 2008 & 0 & 8 & 0 & No \\
\hline 2008 & 0 & 0 & 0 & Yes \\
\hline 2008 & 0 & 0 & 0 & Yes \\
\hline 2008 & 0 & 3 & 0 & Yes \\
\hline 2008 & 0 & 0 & 0 & Yes \\
\hline 2008 & 0 & 0 & 0 & Yes \\
\hline 2008 & 0 & 5 & 0 & Yes \\
\hline 2008 & 0 & 0 & 0 & Yes \\
\hline 2008 & 0 & + & 0 & Yes \\
\hline 2009 & 0 & 0 & 0 & Yes \\
\hline 2009 & + & 0 & 0 & Yes \\
\hline 2009 & 0 & 0 & + & Yes 50\% \\
\hline 2009 & 0 & 2 & 0 & Yes \\
\hline 2009 & 0 & 0 & 0 & Yes \\
\hline 2009 & 0 & 6 & 0 & Yes \\
\hline 2009 & 0 & 0 & 0 & Yes \\
\hline 2009 & 0 & 0 & 0 & Yes \\
\hline 2009 & 0 & 0 & 0 & Yes \\
\hline 2009 & 0 & 0 & 0 & Yes \\
\hline 2009 & 0 & 0 & 0 & Yes \\
\hline 2009 & 0 & 0 & 0 & Yes \\
\hline 2009 & 0 & 1 & 0 & Yes \\
\hline 2009 & 0 & 0 & 0 & Yes \\
\hline 2009 & 0 & 0 & 0 & Yes \\
\hline
\end{tabular}

ones. All fissures were healed conservatively within 3 weeks. Thrombotic haemorrhoid appeared only one time within 14 days after intervention. All cases were cured conservatively by applying ointment with heparin.

With regards to recurrences, only one prolapse associated with bleeding was seen and successfully re-treated by RFITTH. In one bleeding recurrence case we chose to cure it with Baron ligation. 
Table II. Relation between pain and variant of procedure

\begin{tabular}{|cccccccc|}
\hline $7^{\text {th }}$ day & Application & No anter & No pain & Mild pain & Medium pain & $\boldsymbol{\Sigma}$ \\
\hline Internal & 4 & 19 & 8 & 4 & 35 \\
\hline Internal + external & 4 & 16 & 9 & 7 & 36 \\
\hline$\Sigma$ & 8 & 35 & 17 & 71 \\
\hline $21^{\text {st }}$ day & Application & No anter & No pain & Mild pain & Medium pain & $\boldsymbol{\Sigma}$ \\
\hline Internal & 5 & 26 & 3 & 1 & 35 \\
\hline Internal + external & 9 & 23 & 4 & 0 & 36 \\
\hline$\Sigma$ & 14 & 49 & 7 & 1 & 71 \\
\hline
\end{tabular}

All patients who underwent RFITTH from 2007 to 2009 were sent a questionnaire in January 2010. Twenty-five patients took the time to answer all questions and return the questionnaire to us. Please refer to Table I for results. Partial prolapse was detected once and subsequently solved with ligation. One patient reported bleeding recurrence, pain, and painful defecation with VAS $>3$.

With $96 \%$ of overall satisfaction RFITTH was rated very high by all respondents: 24 out of 25 patients would recommend the Celon method to their best friends and/or relatives.

\section{Discussion}

The classic surgical procedures (Milligan Morgan, Whitehead, Parks, Ferguson) for haemorrhoids reduce blood flow rate in the haemorrhoidal plexus and excise prolapsing tissue of the anal channel. These procedures have been proven and are efficient, but also imply significant complications. All of them are associated with pain among patients. Modern surgical techniques were developed to maintain the principles of therapy of haemorrhoidal disease and simultaneously to reduce patients' post-surgical discomfort. The popular surgical techniques are PPH according to Longo [7] and DG-HAL. The PPH according to Longo is a very elegant technique and is not painful for a patient. Haemorrhoidal plexuses are excided together with mucosa above the linea dentata using a circular stapler. But it is accompanied by fatal complications $[8,9]$. These fatal complications result in withdrawing from the first optimism. DGHAL was developed as a technique selectively looking for vascular supply of the rectum and with possible application on prolapsing anoderm tissue through folding and cross punctures (HAL-RAR) [10]. Methods of physical destruction of haemorrhoids and afferent arteries are used in parallel with these surgical methods to limit the blood flow rate in haemorrhoidal plexuses. Thermocoagulation is successful, using LASER [11], infrared radiation [12, 13], radiofrequency radiation [14], bipolar coagulation (HEMORON), cryotherapy [15] and other methods. These methods are applied to haemorrhoids and afferent arteries by application of the active part of an electrode or a laser-guiding fibre across mucosa of the anal channel. The flow rate in haemorrhoids is reduced, but the damaged anoderm mucosa gradually separates and long-time spotting occurs.

The Celon method utilises the effectiveness of bipolar radiofrequency coagulation to achieve wellconcentrated thermal effects on the haemorrhoidal plexuses by introducing the RFITT applicator through the mucosa directly into visualised haemorrhoidal veins. Tumescence is used for protection of mucosa against unwanted thermal damage. Thus, the mucosa and lines of the internal sphincter separate well from the application zone. The mucosa destruction is minimal and its separation does not occur. In the anoderm area, only $1.1 \mathrm{~mm}$ punctures remain after the intervention and they manifest with small soiling on stool, continuing for 0-10 days after intervention. Contraction of prolapsing haemorrhoids and reduction of prolapse occur through thermoablation already during the surgery, without necessary mucosa excision. A significant difference in results between patients in stage III and in stage IV was observed in the study. In stage III, necessary application of the RFITT applicator distally from the linea dentata is not frequent and complete regression of prolapsing anoderm tissue occurs within 10-14 days 


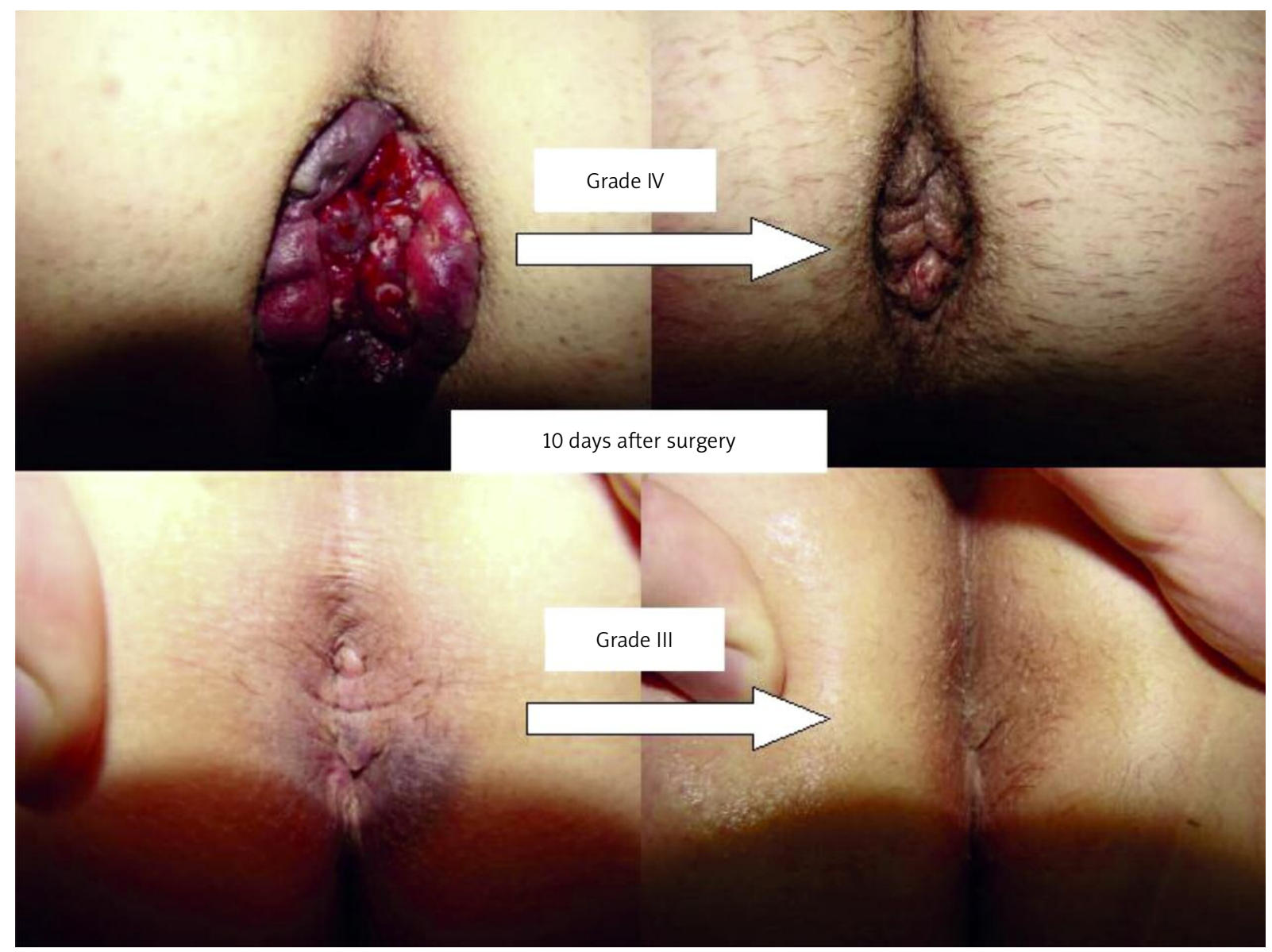

Photo 1. Local findings after RFITTH

after subsiding of oedema or haematoma (Photo 1). In stage IV, particularly if prolapse continues for a longer period of time (months, years), change of a prolapsing haemorrhoid to a skin tag is more probable.

The most frequent complication after RFITTH is anal fissures. We assume that these fissures result either from the manipulation with an already introduced anoscope and/or from the thermal effect on the mucosa of the rectum. Thermal destruction of mucosa can be limited through proper application of tumescence in the area just under the anal mucosa where loosened fibrous fibrillae appear between haemorrhoids and mucosa. Thanks to the application of tumescence we separate the area where the bipolar electrode is introduced from the internal sphincter by forming an insulation layer which prevents subsequent thermal damage of the anal mucosa. This fluid layer limits the thermal effect on the internal sphincter and adjacent struc- tures. We protect above all the urethra with the proper introduction of the RFITT applicator.

\section{Conclusions}

Bipolar radiofrequency-induced thermotherapy is a new solution for the successful treatment of advanced stages of haemorrhoidal disease. The Celon method is easy to use, relatively safe and less painful than conservative treatment approaches with very favourable medium-term results. In addition, its reproducibility and the fast return of patients to their usual activities are important advantages.

\section{References}

1. Cataldo PA. Hemorrhoids. Clin Colon Rectal Surg 2001; 14: 203.

2. Ferguson JA, Mazier WP, Ganchrow MI, et al. The closed technique of hemorrhoidectomy. Surgery 1971; 70: 480.

3. Longo A. Treatment of haemorrhoidal disease by reduction of mucosa and hemorrhoidal prolapse with a circular stapling device: a new procedure. Proccedings of $6^{\text {th }}$ World Congress 
of Endoscopic Surgery, Rome, June 3 to 6, 1998, Bologna: Ed. Monduzzi Editore 1998; 777-84.

4. Greenberg R, Karin E, Avital S, et al. First 100 cases with Dopplerguided haemorrhoidal artery ligation. Dis Colon Rectum 2006; 49: 485-9.

5. Satzinger U, Feil W, Glaser K. Recto Anal Repair (RAR): a viable new treatment option for high-grade hemorrhoids. One year results of a prospective study. Pelviperineology 2009; 28: 37-42.

6. Duben J, Hnatek L, Dudesek B, et al. Initial results of the bipolar RFITT coagulation in advanced stages of hemorrhoidal disorder study. Rozhl Chir 2008; 87: 576-9.

7. Pesta W, Wirkowski A, Leksowski K. Stapled haemorrhoidopexy for the treatment of haemorrhoids: a review of our experience. Videosurgery Miniinv 2009; 4: 147-53.

8. Herold A, Kirsch J, Staude G, et al. A German multicentre study on circular stapled haemorrhoidectomy. Colorectal Dis 2000; 2: 18.

9. Guy RJ, Seow-Choen F. Septic complications of haemorrhoids. Br J Surg 2003; 90: 147-56.

10. Morinaga K, Hacuda K, Ikeda T. A novel therapy for internal hemorrhoids: ligation of the hemorrhoidal artery with a newly devised instrument (Moricorn) in conjunction with a Doppler flowmeter. Am J Gastro 1995; 90: 610-3.

11. Iwagaki H, Higuchi Y, Fuchimoto S, Orita K. The laser treatment of hemorrhoids: results of a study on 1816 patients. Jpn J Surg 1989; 19: 658-61.

12. Leicester RJ, Nicholls RJ, Mann CV. Infrared coagulation: a new treatment for haemorrhoids. Dis Colon Rectum 1981; 24: 602-5.

13. Walker AJ, Leicester RJ, Nicholls RJ, Mann CV. A prospective study of infrared coagulation, injection and rubber band ligation in the treatment of haemorrhoids. Int I Colorectal Dis 1990; 5 : 113-6.

14. Gupta PJ. Radiofrequency ablation and plication of hemorrhoids. Tech Coloproctol 2003; 7: 45-50.

15. Oh C. One thousand cryohaemorrhoidectomies: an overview. Dis Colon Rectum 1981; 24: 613-7.

Received: 2.04.2012, revised: 1.05.2012, accepted: 9.05.2012. 